\title{
Public awareness of cancer risk factors in the Moroccan population: a population-based cross-sectional study
}

\author{
Karima El Rhazi ${ }^{1 *}$, Bahia Bennani², Samira El Fakir ${ }^{1}$, Ahmadou Boly ${ }^{1}$, Rachid Bekkali $^{3}$, Ahmed Zidouh $^{3}$ \\ and Chakib Nejjari ${ }^{1}$
}

\begin{abstract}
Background: In Morocco, knowledge of cancer risk factors, a crucial element in the process of behavioral change, has never been evaluated. This study aims to provide information on the level of awareness of cancer risk factors among the Moroccan general population.

Methods: A cross sectional survey was carried out in May 2008, using a stratified sampling method in a representative sample of the Moroccan adult population. The used questionnaire included social and demographic data as well as questions about 14 cancer related factors regarding passive or active smoking, alcoholic beverages, obesity, physical inactivity, food coloring, red meat, fat, salt, fruit, vegetables, olive oil, green tea, coffee, breast-feeding. Subjects had to choose between 3 propositions for each proposed factor (risk factor/Protective factor/Don't Know). The knowledge score was calculated by summing the correct answer for each proposed factor except coffee and food coloring. The answer was assigned 1 if it's correct or 0 if it was incorrect or the participant responded 'don't know. The maximum knowledge score was 12. Multivariate linear regression model was used to evaluate the determinants of knowledge score.
\end{abstract}

Results: Among 2891 subjects who participated to the survey, 49.5\% were men and $42 \%$ were from a rural area. The mean age was $41.6 \pm 15.2$ years. The mean knowledge score of cancer related factors was $8.45 \pm 3.10$ points. Knowledge score increased with educational level $(\beta=-0.65$ if school year $\leq 6$ versus $>6$ ) and housing category ( $\beta=1.80$ in high standing housing vs rural housing). It was also higher in urban area, among never smokers and among people never consuming alcohol compared to others groups.

Conclusion: These results provide valuable information necessary to establish relevant cancer prevention strategies in Morocco aiming to enhance and improve people's knowledge about risk factors especially in some target groups.

Keywords: Awareness, Determinants, Cancer, Risk factors, Morocco

\section{Background}

Cancer development is associated with several factors. Since the study by Doll and Peto [1], which made a detailed assessment of various cancers related risks, several epidemiological studies have identified factors which show a causal relationship with cancer development. It has been estimated by various authorities that about one-

\footnotetext{
* Correspondence: elrhazikarima@gmail.com

'Department of Epidemiology and Public Health, Faculty of Medicine and pharmacy of Fez, Sidi Mohamed Ben Abdillah University, B.P 1893, Route Sidi Harazem, Km 2.2, Fez, Morocco

Full list of author information is available at the end of the article
}

third of cancers, in western high-income societies, are due to factors related to food and physical activity [2]. As recommended by "World Cancer Research Fund/American Institute for Cancer Research" [2], regular consumption of vegetables, daily physical activity, limited intake of red meat and alcoholic beverages, decrease the risk of cancer development. Therefore, the cancer prevention is possible by behavioral change. This justifies the implementation of preventive actions [3-9]. However, to ensure the effectiveness of such initiatives, the first step consists in understanding the concerns and beliefs of the target population. Indeed, awareness campaigns are crucial in

\section{Biomed Central}


cancer prevention programs. Moreover, knowledge of cancer risk factors is a determinant element in the process of behavioral change $[1,2]$.

In Morocco, the national annual incidence of cancer is estimated between 30000 and 40000 new cases. The most common cancers in Morocco are breast cancer, lung cancer, cervix cancer, colorectal cancer and prostate cancer [10]. Cancer is still a major public health problem because the diagnosis is often delayed and treatment at diagnosed stage is difficult to set up and very expensive [4]. Statistical cancer studies are based on data reported by cancer registry in a given geographical area. Those studies improve epidemiology cancer knowledge in the concerned area. However, knowledge of practices and risk factors associated to cancer has never been evaluated in Morocco. To promote cancer prevention programs, data on the level of knowledge among the target population are needed. Therefore, we conducted a survey on cancer risk factors knowledge in a representative sample of the Moroccan population. This study aims to provide information on the awareness on cancer, among Moroccan general population, regarding some risk factors.

\section{Methods}

\section{Sampling design}

A cross sectional survey was carried out in May 2008, using a stratified two-stage sampling method, on a national random sample of the Moroccan population aged 18 years and above. Sample size was calculated to represent the general population on the basis of $15 \%$ risk factor prevalence, $2 \%$ precision, $95 \% \mathrm{CI}$ and a cluster effect of 2. Thus, sample size was estimated at 2448 and rounded to 3000 persons to compensate for people refusing to take part or being absent during the survey. The people to be surveyed were selected at random from 150 communes, in clusters of twenty households per commune. A cluster was defined as a neighbourhood in an urban area and a locality in a rural area. One cluster was selected at random from each commune included in the survey and one person aged 20 years or above from each household of the cluster was selected at random. The total cluster selection was done proportionally to the distribution of the Moroccan population in urban and rural areas (53 and 47\%, respectively) [11]. The details of the numbers of included communes and therefore of included clusters by origin (urban or rural) in each named region of Morocco are given in the Table 1.

Ethical approval was applicable to the present study under the guidelines in use for epidemiologic studies and which comply with the declaration of Helsinki. It was approved by the ethics committee of Fez University Hospital Center. All subjects gave their consent before answering the survey.
Table 1 Repartition of communes included in the study by origin (urban/rural) in each region of Morocco

\begin{tabular}{lccr}
\hline & Urban & Rural & Total \\
\hline Sahara* & 3 & 1 & 4 \\
Souss-Massa-Draa & 7 & 8 & 15 \\
Gharb-Chrarda-Beni Hssen & 4 & 4 & 9 \\
Chaouia-Ouardigha & 4 & 4 & 8 \\
Marrakech-Tensift-Al Haouz & 7 & 8 & 15 \\
Oriental & 6 & 3 & 10 \\
Grand Casablanca & 19 & 2 & 20 \\
Rabat-Salé-Zemmour-Zaër & 11 & 2 & 13 \\
Doukkala-Abda & 4 & 6 & 9 \\
Tadla-Azilal & 3 & 4 & 7 \\
Meknès-Tafilalet & 7 & 4 & 11 \\
Fès-Boulemane & 6 & 2 & 8 \\
Taza-Al Hoceima-Taounate & 2 & 6 & 8 \\
Tanger-Tétouan & 8 & 5 & 13 \\
Total & 91 & 59 & 150
\end{tabular}

*Sahara = Oued Eddahab-Lagouira, Laâyoune-Boujdour-Sakia-Lhamra, GuelmimEs-Smara.

\section{Knowledge level variables}

The questionnaire of this survey contained questions on the awareness of various cancer risk factors according to international literature. Therefore, 14 cancer presumed related factors were studied, including passive and active smoking, alcoholic beverages, obesity, physical inactivity,

Table 2 Questionnaire about Risk or Protector factor Knowledge of cancer in Moroccan Population

A votre connaissance, les éléments suivants constituent $t$-ils un facteur de risque ou facteur protecteur de cancer?

\begin{tabular}{lccc}
\hline bcb & $\begin{array}{c}\text { Facteur } \\
\text { de risque }\end{array}$ & $\begin{array}{c}\text { Facteur } \\
\text { protecteur }\end{array}$ & $\begin{array}{c}\text { Ne sait } \\
\text { pas }\end{array}$ \\
\hline Tabac actif & $\square$ & $\square$ & $\square$ \\
Tabac passif & $\square$ & $\square$ & $\square$ \\
Alcool & $\square$ & $\square$ & $\square$ \\
Obésité & $\square$ & $\square$ & $\square$ \\
Sédentarité & $\square$ & $\square$ & $\square$ \\
Viandes rouges & $\square$ & $\square$ & $\square$ \\
Consommation excessive de graisses & $\square$ & $\square$ & $\square$ \\
Consommation excessive de sel & $\square$ & $\square$ & $\square$ \\
Fruit & $\square$ & $\square$ & $\square$ \\
Légumes & $\square$ & $\square$ & $\square$ \\
Thé vert & $\square$ & $\square$ & $\square$ \\
Café & $\square$ & $\square$ & $\square$ \\
Huile d'olive & $\square$ & $\square$ & $\square$ \\
Allaitement maternel & $\square$ & $\square$ & $\square$ \\
Colorants alimentaires & $\square$ & $\square$ & $\square$ \\
\hline
\end{tabular}


Table 3 Socio-demographic characteristics of the study participants $(n=3000)$

\begin{tabular}{lcr}
\hline & N & $\%$ \\
\hline Origin & & \\
Rural & 1209 & 41.7 \\
Urban & 1687 & 58.3 \\
Total & 2896 & 100.0
\end{tabular}

Age groups (years)

$<35$

1083

$35-49$

$>=50$

Total

Gender

Male

Female

Total

Marital status

Married

Single or divorced or widowed

Total

Educational level

Illiterate

$<6$ years school

$\geq 6$ years school

Total

$$
943
$$

2891

1433

1463

2896

1986

886

2872

1250

838

788

2876

Occupational activity

Active or student

Retired or unemployed

Housewife

Total

Average family income

$$
\begin{aligned}
& <2000 \\
& 2000-4999 \\
& \geq 5000 \\
& \text { Total }
\end{aligned}
$$

Housing category

Luxurious or modern

New medina

Old medina

Poor housing or slums

Rural housing

Total

Tobacco consumption

Current smokers

Ex smokers

Never smokers

Total

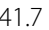

58.3

100.0

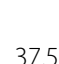

32.6

32.6

29.9

100.0

49.5

50.5

100.0

69.2

30.8

100.0

43.5

29.1

27.4

100.0

47.2

13.4

38.8

100.0

60.2

29.5

10.3

100.0

15.5

14.4

18.9

10.5

40.8

100.0

15.9

9.1

75.1

100.0
Table 3 Socio-demographic characteristics of the study participants $(\mathbf{n}=\mathbf{3 0 0 0})$ (Continued)

Alcohol consumption

Current consumers

Ex consumers

Never consumers

Total

Physical activity

Yes

No

35.4

Total

100.0

Family history of cancer

Yes

No

Total

100.0

Health problem

$\begin{array}{lll}\text { Yes } & 957 & 33.1\end{array}$

$\begin{array}{lll}\text { No } & 1936 & 66.9\end{array}$

\begin{tabular}{lll} 
Total & 2893 & 100.0 \\
\hline
\end{tabular}

food coloring, red meat, fat, salt, fruit, vegetables, olive oil, green tea, coffee, breast-feeding. Most included items were chosen based on: i) their potential link as risk or protective factor for some type of cancers as described elsewhere [2,12-14], ii) included food items (food coloring, red meat, fat, salt, fruit, vegetables, olive oil, green tea, coffee, breast-feeding) are commonly used in Moroccan population, iii) included attitudes items (passive and active smoking, alcoholic beverages, obesity, physical inactivity) are frequently adopted in Morocco. Questionnaire about the knowledge of these items is given in Table 2.

For each candidate cancer risk factor, three answers were proposed: $1 /$ it is a risk factor, $2 /$ it's a protective factor 3/ don't know. The people's knowledge of cancer risk factors was assessed by choosing the correct answer among these three propositions for each of the proposed factors. Each answer was scored 1 if it was correct or 0 if it was incorrect or the participant responded 'don't know'. For smoking item, passive and active smoking which concern the same risk factor, were accounted as one item. The answer was correct if the answer of passive and/or active smoking was correct and incorrect if not. Coffee and food coloring were not considered when calculating the knowledge score because of the controversial results on their cancer link. Then, total knowledge score ranged from 0 (the subject did not recognize any factor) to 12 .

\section{Independent variables}

Data concerning socio demographic factors (age, gender, region of residence, educational level, marital status, employment status, average family income, self-reported 
Table 4 Knowledge score of cancer risk factor according to the main demographic and socio-economic characteristics

\begin{tabular}{lcccc}
\hline & N & Means & SD & p-value \\
\hline Origin & & & & \\
Rural & 1173 & 8.2 & 3.3 & $<0.00$ \\
Urban & 1644 & 8.6 & 2.9 & \\
Total & 2817 & & &
\end{tabular}

Age groups (years)

$<35$

$35-49$

$>=50$

Total

Gender

Male

Female

Total

Marital status

Married

Single or divorced or widowed

Total

Educational level

Illiterate

$<6$ years school

$\geq 6$ years school

Total

Occupational activity

Active or student

Retired or unemployed

Housewife

Total

Average family income

$<2000$
$2000-4999$
$\geq 5000$
Total

Housingcategory

Luxurious or modern

New medina

Old medina

Poor housing or slums

Rural housing

Total

Tobacco consumption

Current smokers

Ex smokers

$\begin{array}{lll}1058 & 8.4 & 3.1 \\ 919 & 8.6 & 3.0 \\ 835 & 8.4 & 3.2 \\ 2812 & & \end{array}$

$\begin{array}{lll}1379 & 8.5 & 2.9\end{array}$

$\begin{array}{lll}1438 & 8.4 & 3.3\end{array}$

2817

$\begin{array}{lll}1926 & 8.4 & 3.2\end{array}$

$\begin{array}{lll}867 & 8.6 & 3.0\end{array}$

2793

$\begin{array}{lll}1210 & 8.0 & 3.4\end{array}$

$817 \quad 8.5 \quad 3.0$

$\begin{array}{lll}771 & 9.1 & 2.5\end{array}$

2798

$\begin{array}{lll}1319 & 8.5 \quad 2.9\end{array}$

$\begin{array}{lll}372 & 8.6 \quad 2.9\end{array}$

$\begin{array}{lll}1095 & 8.3 \quad 3.3\end{array}$

2786

1405

700

242

2347

$\begin{array}{lll}438 & 9.2 & 2.4\end{array}$

$\begin{array}{lll}404 & 8.2 & 3.2\end{array}$

541

286

1148

2817

$\begin{array}{lll}429 & 8.3 & 2.8\end{array}$

$246 \quad 83 \quad 3.1$
Table 4 Knowledge score of cancer risk factor according to the main demographic and socio-economic characteristics (Continued)

\begin{tabular}{llll}
\hline Never smokers & 2030 & 8.8 & 2.9 \\
Total & 2705 & &
\end{tabular}

Alcohol consumption

Current consumers

Ex consumers

$\begin{array}{cccc}92 & 7.7 & 3.1 & \\ 126 & 8.4 & 2.9 & 0.06 \\ 2535 & 8.4 & 3.1 & \\ 2753 & & & \end{array}$

0.30

Never consumers

Total

Physical activity

Yes

$1570 \quad 8.4 \quad 3.1$

No

$\begin{array}{lll}992 & 8.6 & 3.1\end{array}$

0.29

Total

2562

Family history of cancer

$\begin{array}{lccc}\text { Yes } & 370 & 8.4 & 3.1 \\ \text { No } & 2445 & 8.5 & 3.1 \\ \text { Total } & 2815 & & \end{array}$

0.16

Health problem

\begin{tabular}{lcccc} 
Yes & 935 & 8.3 & 3.1 & \\
No & 1880 & 8.5 & 3.1 & 0.11 \\
Total & 2815 & & & \\
\hline
\end{tabular}

Sample of the adult Moroccan population, 2008.

$<0.001$

health status, family history of cancer, physical activity, smoking and alcohol attitudes were also collected.

The questionnaire was developed by the authors and was stated in French which is the second Moroccan state language. It was administered in local dialect by trained pair (one man and one woman) including physicians and nurses chosen from the same regions as the participants. The data were collected in the subjects' homes during a personal interview which was carried out homogeneously from Monday to Sunday. The questionnaire's face validity was checked in a pilot study in 20 participants and showed that the questionnaire was acceptable and understandable. All information collected on individuals has been kept confidential and anonymous.

\section{Statistical analysis}

$<0.001$ All data statistical analyses were conducted using SPSS 17.0 software. Knowledge level score and related socio demographic variables were analyzed using the Student $\mathrm{t}$ - test or one-way analysis of variance. Variables with $\mathrm{P} \leq 0.20$ on univariate analysis were entered in multivariate linear regression model to evaluate the knowledge level score of the cancer risk factors and its determinants. 


\section{Results}

\section{Population characteristics}

Among the 3000 persons enrolled in this study, only 2891 (96.5\%) took part in the survey. People, who are not included in the survey refused to participate to the survey or were absent (3.5\%). This proportion was higher in urban areas (4.9\%) than rural areas (1.4\%).

Among all participants, 1433 were men (49.5\%), 1461 women $(50.5 \%)$ and $42 \%$ were from rural areas. The average age was 41.6 (standard deviation $(\mathrm{SD})=15.2$ ) years and $43.4 \%$ were illiterate. The average family income was less than $2000 \mathrm{MAD} /$ month (equivalent currency exchange is: $1 \mathrm{MAD}=0.09 \mathrm{~h}$ ) for $52.5 \%$ of participants. A quarter of participant (25\%) and $7.9 \%$ were currently or formerly smokers and alcohol consumers respectively. (Table 3).

Among all participants, only $2.2 \%$ showed a correct knowledge about all mentioned risk factors. For factors considered as cancer risk factors, $90.8 \%$ and $86.3 \%$ had correct knowledge about active and passive smoking respectively, $81.0 \%$ for alcohol consumption, $62.7 \%$ for obesity, $61.3 \%$ for fat, $59.9 \%$ for physical inactivity, $59.2 \%$ for salt and only $36.9 \%$ for red meat. For other factors considered as protecting factors, $88.9 \%$ of participants give a correct answer for olive oil, $86.4 \%$ for vegetables, $83.4 \%$ for fruit, $73.1 \%$ for breast feeding and $65.4 \%$ for green tea. For controversial factors, $17.6 \%$ and $40.0 \%$ of participants believe that food coloring and coffee are risk factors respectively.

The average knowledge score of cancer risk factors in participants was $8.5 \pm 3.1$ points. Significant differences in average knowledge score were observed depending on the area of origin, level of education, housing category and family income. Hence, subjects from urban area, who spent more 6 years at school, with family incomes greater than 5000 MAD and who were living in modern housing had significantly higher knowledge score regarding cancer risk factors $(P<0.001, P<0.001, P=0.01$ and $P<0.001$ respectively). Some attitudes were also related to high level of knowledge score, especially tobacco $(\mathrm{p}=0.01)$ and alcohol consumption $(\mathrm{p}=0.06)$. However, gender, marital status, profession and physical activity did not show significant influence on the knowledge score of cancer risk factors (Table 4).

After adjusting for confounding factors, knowledge score increased with educational level and housing category. It was also higher in urban area, among never smokers, people never consuming alcohol and among people without past history of health problem compared to others groups (Table 5).

\section{Discussion}

This cross-sectional study allowed determining the knowledge level of cancer risk factors among the Moroccan
Table 5 Correlates of knowledge level score of cancer risk factors among the Moroccan population: multivariate analysis

\begin{tabular}{|c|c|c|c|c|}
\hline Alcohol consumption & Beta & \multicolumn{2}{|c|}{ 95\% Cl limits Beta } & $\frac{p \text {-value }}{0.006}$ \\
\hline Never consumers & Reference & & & \\
\hline Ex consumers & -1.01 & -1.63 & -0.39 & 0.01 \\
\hline Current consumers & -0.09 & -0.62 & 0.45 & 0.75 \\
\hline Tobacco consumption & & & & 0.03 \\
\hline Never smokers & Reference & & & \\
\hline Ex smokers & -0.48 & -0.80 & -0.15 & 0.004 \\
\hline Current smokers & -0.46 & -0.84 & -0.07 & 0.021 \\
\hline Housing category & & & & $<0.001$ \\
\hline Rural housing & Reference & & & \\
\hline Luxurious or modern & 1.80 & 0.66 & 2.93 & 0.002 \\
\hline New medina & 1.18 & 0.03 & 2.33 & 0.044 \\
\hline Old medina & 1.84 & 0.70 & 2.98 & 0.002 \\
\hline Poor housing or slums & 0.65 & -0.433 & 1.73 & 0.240 \\
\hline School year & & & & $<0.001$ \\
\hline$\geq 6$ years school & Reference & & & \\
\hline Illiterate & -0.65 & -0.95 & -0.36 & $<0.001$ \\
\hline$<6$ years school & -0.33 & -0.63 & -0.03 & 0.030 \\
\hline Health problem & & & & 0.040 \\
\hline Yes & Reference & & & \\
\hline No & 0.24 & 0.01 & 0.48 & 0.040 \\
\hline \multicolumn{5}{|l|}{ Origin } \\
\hline Rural & Reference & & & \\
\hline Urban & 1.22 & 0.12 & 2.33 & 0.030 \\
\hline
\end{tabular}

population. The results of this study show that educational level and housing category were significantly associated with a high knowledge score of cancer risk factors. This can be explained by the fact that health knowledge is depending on the socioeconomic level $[15,16]$. Effectively, individuals with high economic standards have easier access to outreach programs which were more easily assimilated by individuals with higher education level. These results are consistent with other previous studies [15-17].

A significant association between the area of origin and knowledge score of cancer risk factors has also been observed. The high knowledge score was noted in urban area as reported in other studies [18-21] and can be explained by the difference in health facilities between the urban and rural areas.

Smoking is a widespread habit in many developing countries, it is found as a risk factor in several malignant tumors [3,22-25]. Its prevalence in Morocco was $18.0 \%$ in both sexes [26,27] and its consumption was 
significantly associated with a low score knowledge in the current study. However, $85.9 \%$ of participants had a good knowledge of tobacco effect. Anastasiou et al. [19] showed that only $58.4 \%$ of patients stated that they were aware of smoking as a risk factor for bladder cancer, versus $94.6 \%, 91.6 \%$ and $92.1 \%$ who related this risk factor to chronic obstructive pulmonary disease, heart and vascular problems and to lung cancer, respectively [19]. Some authors proposed recommendations [28] on how comprehensive tobacco control policies that address smoking-related inequalities can be developed. Moreno et al. [29] suggested that strategies such as pricing and taxations, regulation of products and restrictions of advertising will also play a very important role besides awareness in achieving behavioral change.

Alcohol consumption was also significantly associated with a low knowledge score. Although alcohol is a risk factor for many type of cancers $[1,30]$, public awareness on the harmful effect of alcohol consumption concerns mainly cardiovascular diseases [29-31]. In Morocco, despite a low prevalence of alcohol consumption, awareness of the cancer risks associated to excessive alcohol consumption is needed especially because of the increasing of cancer prevalence and alcohol consumption in the last years in this country.

The main limitation of this study is its cross-sectional design. Responses to this type of cross-sectional survey could be affected by social conditions such as information from the mass media and other sources on diseases and their risk factors. Thus, the results might not necessarily reflect actual public awareness. However, the sample study was representative of the whole Moroccan population since the prevalence of socio-demographic factors was similar to that reported in the last general census of habitat and population in 2004 [11]. Another limitation of the study is related to the questionnaire which did not give people the option of saying that a factor is neither risky nor protective. This is likely to have increased the rate of guessing and giving the more accurate knowledge score. To our knowledge, this is the first study that assesses the level of awareness for some cancer risk or protector factors in Morocco. The calculating score was based only on established risk or protective cancer factors. This score may help us to have an approach for the Moroccan public awareness of cancer risk factors which could be useful in the formulation of public health initiatives for cancer prevention.

\section{Conclusion}

Awareness of cancer risk factors among the Moroccan general population seems to be dominated by some behaviors (active or passive smoking and alcohol consumption rather than dietary factors (red meats). Hence, the people's knowledge level about cancer risk factors must be enhanced in order to improve cancer prevention. This could be possible by modifying the people's knowledge about cancer risk factors. The results of the present survey provide precious information that could be used for setting up valuable cancer prevention strategies in Morocco.

\section{Competing interests}

All authors declare that they have no competing interests.

\section{Authors' contributions}

KE has contributed to conception and design, acquisition of data, analysis and interpretation of data and have been involved in drafting the manuscript; $B B$ has been involved in drafting the manuscript and has given final approval of the version to be published. SE has been involved in drafting the manuscript. $A B$ has been involved in data analysis and drafting the manuscript. AZ has contributed to conception and design of data. RB has contributed to conception and design of data. CN has contributed to conception and design, has been involved in revising the manuscript critically and has given final approval of the version to be published. All authors read and approved the manuscript.

\section{Acknowledgments}

This work was carried out with support of Lalla Salma association against cancer. We would also like to thank Pr M El Azami El Idrissi for his help for reviewing the manuscript.

\section{Author details}

${ }^{1}$ Department of Epidemiology and Public Health, Faculty of Medicine and pharmacy of Fez, Sidi Mohamed Ben Abdillah University, B.P 1893, Route Sidi Harazem, Km 2.2, Fez, Morocco. ${ }^{2}$ Department of Microbiology and Molecular Biology, Team of Microorganisms and Oncogene factors Faculty of Medicine and Pharmacy of Fez, Sidi Mohamed Ben Abdillah University, Fez, Morocco. ${ }^{3}$ Lalla Salma Fondation of Prevention and Traitement of Cancers, Rabat, Morocco.

Received: 30 January 2013 Accepted: 20 September 2014 Published: 23 September 2014

\section{References}

1. Doll R, Peto R: The causes of cancer: quantitative estimates of avoidable risks of cancer in the United States today. J Natl Cancer Inst 1981, 66(6):1191-1308

2. Wiseman M, The second World Cancer Research Fund/American Institute for Cancer Research expert report: Food, nutrition, physical activity, and the prevention of cancer: a global perspective. Proc Nutr Soc 2008 67(3):253-256. Epub 2008.

3. Inoue M, Iwasaki M, Otani T, Sasazuki S, Tsugane S: Public awareness of risk factors for cancer among the Japanese general population: a population-based survey. BMC Public Health 2006, 10(6):2.

4. Tachfouti N: The main risk factors of cancer in Morocco. Data available in the literature. Rev Epidemio/ Sante Publique 2009, 57(S1):S56.

5. Breslow RA, Sorkin JD, Frey CM, Kessler LG: Americans' knowledge of cancer risk and survival. Prev Med 1997, 26:170-177.

6. Pohls UG, Renner SP, Fasching PA, Lux MP, Kreis H, Ackermann S, Bender HG, Beckmann MW: Awareness of breast cancer incidence and risk factors among healthy women. Eur J Cancer Prev 2004, 13:249-256.

7. McMenamin M, Barry $H$, Lennon AM, Purcell $H$, Baum M, Keegan D, McDermott E, O'Donoghue D, Daly L, Mulcahy $H$ : A survey of breast cancer awareness and knowledge in a Western population: lots of light but little illumination. Eur J Cancer 2005, 41:393-397.

8. Sakurai H: Healthy Japan 21. JMAJ 2003, 46(2):47-49.

9. Sanderson SC, Waller J, Jarvis MJ, Humphries SE, Wardle J: Awareness of lifestyle risk factors for cancer and heart disease among adults in the UK. Patient Educ Couns 2009, 74(2):221-227. Epub 2008 Dec 6. 
10. Registre des cancers de la région du grand casablanca. 2012. http://www.contrelecancer.ma/site_media/uploaded_files/RCRC_28_mai_2012.pdf. Accessed October 2013.

11. Haut Commissariat au Plan: Recensement Général de la Population et de l'Habitat 2004: caractéristiques démographiques et socio- économiques de la population. Rapport national. http://www.hcp.ma/downloads/ Demographie-Caracteristiques-demographiques-et-socio-economiquesRGPH-2004 t13063.html. (accessed October 2013).

12. do Carmo França-Botelho A, Ferreira MC, França JL, França EL, Honório-França AC: Breastfeeding and its relationship with reduction of breast cancer: a review. Asian Pac J Cancer Prev 2012, 13(11):5327-5332.

13. Pelucchi C, Bosetti C, Negri E, Lipworth L, La Vecchia C: Olive oil and cancer risk: an update of epidemiological findings through 2010. Curr Pharm Des 2011, 17:805-812.

14. Cuyun Carter GB, Katz ML, Ferketich AK, Clinton SK, Grainger EM, Paskett ED, Bloomfield CD: Dietary intake, food processing, and cooking methods among Amish and non-Amish adults living in Ohio Appalachia: relevance to nutritional risk factors for cancer. Nutr Cancer 2011, 63(8):1208-1217. doi:10.1080/01635581.2011.607547. Epub 2011 Oct 25.

15. Harold P, Freeman HP: Cancer in the socioeconomically disadvantage $3 d$. CA Cancer J Clin 1989, 39(5):266-288.

16. Freeman HP: Cancer in the economically disadvantaged. CA Cancer J Clin 1989, 64(1):324-334.

17. Oranratanaphan S, Amatyakul P, Iramaneerat K, Srithipayawan S: Knowledge, Attitudes and Practices about the Pap Smear among Medical Workers in Naresuan University Hospital, Thailand. Asian Pac J Cancer Prev 2010, 11(6):1727-1730.

18. Ministry of Health of Morocco. http://srvweb.sante.gov.ma/Publications/ Etudes_enquete/Documents/effetsglobaux/2InfrastructurePublicPrivve.pdf. (accessed 25 April 2011).

19. Anastasiou I, Mygdalis V, Mihalakis A, Adamakis I, Constantinides C Mitropoulos D: Patient awareness of smoking as a risk factor for bladder cancer. Int Urol Nephrol 2010, 42(2):309-314. Epub 2009 Jul 10.

20. Akhigbe $\mathrm{AO}$, Omuemu VO: Knowledge, attitudes and practice of breast cancer screening among female health workers in a Nigerian urban city. BMC Cancer 2009, 9:203.

21. Pakfetrat A, Falaki F, Esmaily HO, Shabestari S: Oral cancer knowledge among patients referred to Mashhad Dental School, Iran. Arch Iran Med 2010, 13(6):543-548.

22. San Turgay A, Sari D, Türkistanli EC: Knowledge, attitudes, risk factors, and early detection of cancer relevant to the schoolteachers in Izmir, Turkey. Prev Med 2005, 40(6):636-641.

23. Walker S, Saltman DL, Colucci R, Martin L: Awareness of risk factors among persons at risk for lung cancer, chronic obstructive pulmonary disease and sleep apnea: a Canadian population-based study. Can Respir J 2010, 17(6):287-294.

24. Jimenez EA, Xie Y, Goldsteen K, Chalas E: Promoting knowledge of cancer prevention and screening in an underserved Hispanic women population: a culturally sensitive education program. Health Promot Pract 2010, 18.

25. Blake KD, Viswanath K, Blendon RJ, Vallone D: The role of tobacco-specific media exposure, knowledge, and smoking status on selected attitudes toward tobacco control. Nicotine Tob Res 2010, 12(2):117-126. Epub 2009.

26. Nejjari C, Benjelloun MC, Berraho M, El Rhazi K, Tachfouti N, Elfakir S, Serhier Z, Slama K: Prevalence and demographic factors of smoking in Morocco. Int J Public Health 2009, 54:447-451.

27. El Rhazi K, Nejjari C, Berraho M, Serhier Z, Tachfouti N, El Fakir S, Benjelloun M, Slama K: Inequalities in smoking profiles in Morocco: the role of educational level. Int J Tuberc Lung Dis 2008, 12(11):1327-1332.

28. Bostock Y: International Network of Women Against Tobacco - Europe. In Searching for the Solution: Women, Smoking and Inequalities in Europe. London: Health Development Agency; 2003.

29. Martin-Moreno JM, Soerjomataram I, Magnusson G: Cancer causes and prevention: a condensed appraisal in Europe in 2008. Eur J Cancer 2008, 44(10):1390-1403.
30. Mukamal KJ, Conigrave KM, Mittleman MA, Camargo CA Jr, Stampfer MJ, Willett WC, Rimm EB: Roles of drinking pattern and type of alcohol consumed in coronary heart disease in men. N Engl J Med 2003, 348(2):109-118.

31. Redeker C, Wardle J, Wilder D, Hiom S, Miles A: The launch of Cancer Research UK's 'Reduce the Risk' campaign: baseline measurements of public awareness of cancer risk factors in 2004. Eur J Cancer 2009, 45(5):827-836. Epub 2008 Dec 4.

doi:10.1186/1471-2407-14-695

Cite this article as: El Rhazi et al:: Public awareness of cancer risk factors in the Moroccan population: a population-based cross-sectional study. BMC Cancer 2014 14:695.

\section{Submit your next manuscript to BioMed Central and take full advantage of:}

- Convenient online submission

- Thorough peer review

- No space constraints or color figure charges

- Immediate publication on acceptance

- Inclusion in PubMed, CAS, Scopus and Google Scholar

- Research which is freely available for redistribution

Submit your manuscript at www.biomedcentral.com/submit
C Biomed Central 